\title{
Cross-Cultural Design Learning Tool: Cross-Cultural Design (CCD) Approach: A Study of South Korean Student Projects in Collaboration with Goldsmiths, University of London, UK
}

\author{
Dong Yeong Lee ${ }^{(\bowtie)}$ and Mike Waller \\ Goldsmiths, University of London, London, UK \\ $\{d .1$ ee, m.waller\}@gold.ac.uk
}

\begin{abstract}
This paper explores how design can develop an innovatory practice that builds the skills needed to design with cultural sensitivity. It is relevant to designers, researchers, and developers interested in extending the capabilities of innovating in relationship to culture. This paper presents a series of learning projects and outcomes that demonstrate the development of a cultural design tool. The project took place between Goldsmiths University of London in the United Kingdom and (KDM) Korean Design Membership in South Korea.
\end{abstract}

Keywords: Innovation methods - Cross-Cultural design - Teaching cultural understanding $\cdot \mathrm{CCD} \cdot$ Innovation tool $\cdot$ Cultural design $\cdot$ Global design $\cdot$ Service design

\section{Introduction}

Design engages with many aspects of life, from the design of the sound and experience of an alarm clock that wakes us up in the morning, to the underlying cultural knowledge that informs the design of mobile phone interfaces in different socio-cultural contexts. Sherry Turkle (2011) discusses that it is important to understand the complex cultural connections we have with things. We need to build a critical understanding of the cultural context to be able to design successfully, particularly for a wider global context, not only to conserve but also to develop cultural identities. Therefore, although a design can often have universality, it must be sensitive to cultural nuances. The underlying focus of the proposed experimental Cross-Cultural Design (CCD) tool is to learn, develop and apply skills in engaging designers culturally and their understanding of "cultural difference'. It is not only design that is concerned with understanding culture, but other subject areas like contemporary critical, social, and cultural theory can also support the activity of Cross-Cultural Design (Diehl and Christianns 2006). In today's multicultural societies, understanding this cultural difference is a skill required by designers to engage meaningfully with users, particularly with the increased use of consumer technologies. As a result of globalisation, considerable efforts are being made to explore and understand cross-cultural relationships. This paper takes the specific example of cross-cultural design innovation projects held at Goldsmiths, University of London, in the United 
Kingdom and at the KDM design center in Seoul, South Korea. The aim of the paper is to present the proposed learning tool and discuss the development of cultural knowledge capital by the participants. There were 150 participants in total from the Korea Design Membership- a Korean Government organisation, the Regional Design Center in Gwangju, Daegu, Pusan cities, South Korea.

A series of case studies comparing a range of projects, briefs, outcomes, and evaluations will be presented in the paper. These case studies explore the implementation and ongoing development of Cross-Cultural Design (CCD). The projects explore learning that requires students to identify and explore different cultural backgrounds of a range of users. Here, the cultural difference could be between countries, genders and the like. How to define this 'cultural difference' is the very first task assigned to students in order to understand the context of the individual design activity and reinterpret it in its actual context (Curedale 2012). By analysing, comparing, displacing and repositioning their original meaning, students can attain a cohesive understanding of their function, role, cultural values, beliefs, aspirations and ideals; whilst learning about the rationale behind current designs and finally reinterpreting them in contemporary contexts.

From the initial workshops and project briefs a model was developed to help the students explore cross cultural concerns within their work. This learning tool helped students understand the nuances of cultures, and understand and interpret different cultures with the aim of developing new directions to explore, creating cultural innovations, and evolving design concepts. The model was divided into categories of approach to cultural formations;

1. Combination and Harmonisation - Design process based on sharing ideas and facilitating communication between two or more cultures.

2. Hybrid and Fusion - Design process based on sharing ideas. Similar to combination and harmonisation, Hybrid and Fusion will lead to a synergy of ideas and innovative results.

3. Transform/Translate/Transplant - Design process based on the idea of adopting one culture into another, and analysing the effects.

4. Inclusion and Exclusion - Design process based on defining boundaries examined from two different angles: protecting your own culture, and disregarding another culture.

We are witnessing the rapid development of many technology based products and services, and simultaneously global audiences are becoming more sophisticated and complex, as different cultural expectations and social needs need to be considered. Design is rapidly developing with many innovative products and services that combine manufactured hardware and software which require cultural knowledge to be well received by their user communities. Theorist Theodore Levitt (1983), in his Harvard Business Review article, The Globalization of the Markets, paid particular attention to the phenomenon of 'standardised products and brands'. Several observations were made including; (Levitt, 1983 IN Douglas and Wind 1987, p. 419);

1. Customers in the global markets' needs and interests are becoming increasingly homogenous worldwide; 
2. People around the world are willing to sacrifice preferences in product features, functions, design, and the like for lower prices at high quality; and

3. Substantial economies of scale in production and marketing can be achieved through supplying global markets.

The proposed model of cultural engagement should help address this shifting requirement of innovation. There is an interest to support the hyper-local, regional and national to promote their own cultures, whilst respecting and understanding the cultures of others. At a national level governments are aware that their own creative industries can have a major impact on their economies. Consumers and prosumers are becoming more sophisticated and want to access and be part of the formation of a wider and more culturally rich range of products and services.

\section{The Importance of Cross-Cultural Design}

The benefits to the users of cross culture design are that products and services can engage with exposing users to cultural fashion, other cultural practices that they may want to learn more about. These practices may be about how we would like to live our lives, be different from others, and adopt other cultural practices that add something to our own lives. Often when designs of products and services are exported to other cultures their understanding can be misinterpreted as cultural values can be very different. In each culture there are different thoughts on what is fashionable, interesting and what quality might mean. What one culture may find amusing, another might find offensive. This is why understanding other cultures is so important for designers to engage with. There are also good arguments to suggest that local designers should be involved in innovation teams, that bring some of their own cultural understanding to a particular project.

\section{Current Status of Design Education and Why Learning About 'Culture' Is Important}

Common teaching methods within undergraduate higher education design include briefs within set themes, creating a basis for students to make sense and solve problems practically, individually, or in groups. Implementing novel and playful methods into design processes allows students to step out of their comfort zone and follow often-unexpected routes to a new way of developing a design outcome. Current trends in design education across industry encourage use of interdisciplinary design and collaborative practice. A cross-cultural approach to collaborative projects enables use of group work through a multicultural way of thinking, and opens doors to exciting new ways of combining design ethics and processes developed within individual design discipline backgrounds.

As Kolko (2010) declared, broader design and a diversity of methods should be an integral tool for educating future designers that should be sought out by educators. By introducing innovative methods of teaching students about design issues and giving a wider view on the affordance of design, the trained designers of the future will be able 
to tackle design problems and briefs with an open view of the designer's roles and responsibilities.

At Goldsmiths there are a series of tools used to identify the relationship between the designer and user, and the contexts of site, event, society and culture were used in all of the cross-cultural design briefs. What is central to this relationship diagram is the dialogical relationship being developed between designer and user, identified as an empathetic understanding built on an engaged connection with the user. In the centre of the diagram below is a mediating lens through which the designer sees the context of user and the object of innovation. This lens encourages the designer to acknowledge that they have particular cultural biases or influences that they see the the project through. They can also invest in exploring particular ways to look or understand the culture of the user, citizen or participant (Fig. 1).

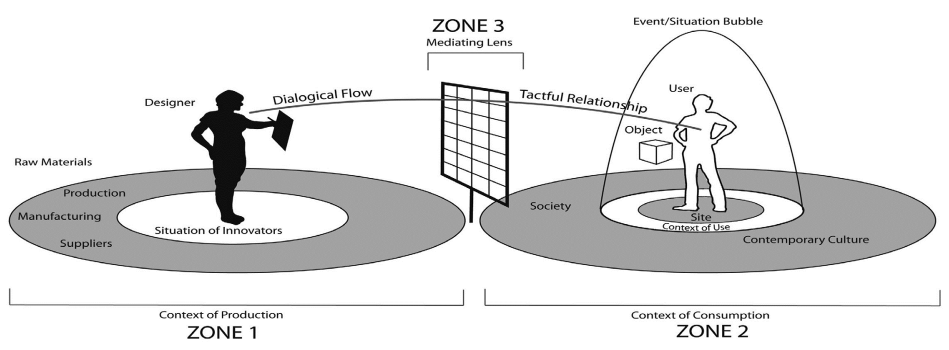

Fig. 1. Terry rosenberg context of design diagram (drawing mike waller)

We adopted Runco's playful approach to the design briefs for these cross-cultural projects. (2013, p. 111) Runco reminds us that the notion of creativity is not new; it is practised, accepted, and shared across cultures. However, using creativity as a starting point, or a means to instigate cross-cultural exchange, relationships and collaboration can encourage more solid learning, understanding, and appreciation of new (i.e. different to one's own) culture. "Given that there are often large differences in the prevailing ideas and practices between different cultures, a product/idea judged as being very creative in one culture might be perceived very differently in another culture" (Wolbers 2013, p. 86).

Rajeshwari Ghose is a Hong Kong-based critic featured in Buchanan and Margolin's 'The Idea of Design (1995b)'. She discusses the pace and attitude towards design and development in Asia compared with that of the Western world, saying that, "China had no modern design education until the late 1970s. Design education has been formed mainly in western countries" (Buchanan and Margolin 1995a, p. 192).

It is apparent that there is a need for a platform that enables creative collaboration between cultures, so that an appreciation of a wider set of properties can be established between cultures. As Buchanan and Margolin (1995a,b) highlight, it will result in the introduction of new possibilities of collaboration because of an in-depth understanding of what others do. 


\section{Setting up CCD Learning Programme}

We have been running Cross-Cultural Design programmes and teaching students from a variety of Korean design universities within the Design Department at Goldsmiths, University of London for the past five years. The Cross-Cultural Design programmes have been developed around different themes related to different cultural concerns, from tourism to cultural practices. From this experience, we found that students were able to engage and understand cultural difference through the design project brief, and they were able to develop new types of Cross-Cultural Design enquiries. Through the delivery of these cross-cultural design projects it is clear that cross-cultural design activities within the design curriculum help students understand and respect cultural difference, and support the success for the future development of a culturally enriched design field.

The programmes used the developed CCD learning tool, which were evolved and iterated at the Pi Studio (Prospecting and Innovation Design Research Studio) at Goldsmiths, University of London for the students from Kyung Hee University, Korea. As with all of the project design briefs, the teaching teams have tried to focus on a clear and meaningful topic, identified as requiring exploration through designing (Table 1).

Table 1. Brief of 4 CCD short courses since 2011

\begin{tabular}{l|l|l}
\hline & Programme title & Brief \\
\hline 1 & Colonial of cultures & $\begin{array}{l}\text { The aim of this project brief was to introduce a new approach to } \\
\text { socio-cultural 'difference' through design and designing }\end{array}$ \\
\hline 2 & Bon voyage & $\begin{array}{l}\text { This project is about a journey or a variety of journeys, which were } \\
\text { geographic and creative. During this particular project, the } \\
\text { impact, implications, and counter-arguments of globalisation } \\
\text { were researched, with the aim of developing these issues whilst } \\
\text { still enjoying the celebration of cultural differences through the } \\
\text { design concepts }\end{array}$ \\
\hline 3 & Tourism of the ordinary & $\begin{array}{l}\text { As designers we are interested in understanding, exploring and } \\
\text { reinventing the world. This project engages with a number of } \\
\text { lost cultural practices in Korea, drawing on them to invent new } \\
\text { cultural practices as well as reinventing existing ones }\end{array}$ \\
\hline 4 & Future shopping & $\begin{array}{c}\text { This brief introduces students to a live project exploring the posi- } \\
\text { tive disruption that design can make in proposing new and future } \\
\text { forms of retail cultures. Designers think about 'positive disrup- } \\
\text { tions', as well as how to work with ideas that address change } \\
\text { and transformation caused by emerging technology }\end{array}$ \\
\hline
\end{tabular}

\section{Development of Cross-Cultural Design Learning Tool}

The cross-cultural design tool is introduced within each of the projects to assist the students in deconstructing their understanding of culture. The four approaches to cultural enquiry include; (1) Combination and Harmonisation, (2) Hybrid and Fusion, (3) Transform/Translate/Transplant, (4) Inclusion and Exclusion. 
Combination and harmonisation involves sharing and communicating ideas between cultures with a view to be able to create cultural forms that span one or more cultural practices from different cultures and encourage communication and interest from the other cultures, including practices, behaviours, materials and artefacts. Hybrid and fusion is intended as a way to inspire more radical collisions of culture. The lace bowls, designed by Ching-Ting Hsu, and craft art by Tsun-Jen Lee are examples of what happens when an oriental embroidery pattern is combined with western aesthetic lace. Through transform/translate/transplant, students endeavour to carry a cultural practice from one context into another, and explore the possible impact. Inclusion and exclusion focuses on building cultural bridges to invite the other into, or creating cultural fences that guard one's own culture and traditions, therefore exclude other cultures. In some cases it is possible to create a new culture that includes some members but excludes others, like a subculture.

\section{Testing the Cross-Cultural Design Learning Tool}

The CCD learning tool has been tested firstly to verify the viability of the Cross-Cultural Design concepts, and secondly to test the Cross-Cultural Design programme, analyse the design outcomes, and develop Cross-Cultural Design tools. There were 38 CCD design outcomes by 150 participants in total from KDM (Korea Design Membership-a Korean Government organisation), with support of MA Design students from Goldsmiths, University of London. The outcomes of the CCD learning tool in the four categories can be seen in the case studies below.

\subsection{Exploring the Category 1. Combination and Harmonisation}

Global-wall public display for a street market in London and Seoul.

This project explored how a new form of public market media display could allow market traders to communicate with people in different markets globally. The aim was to open up new forms of trade or harmony between market stall holders in Seoul and in

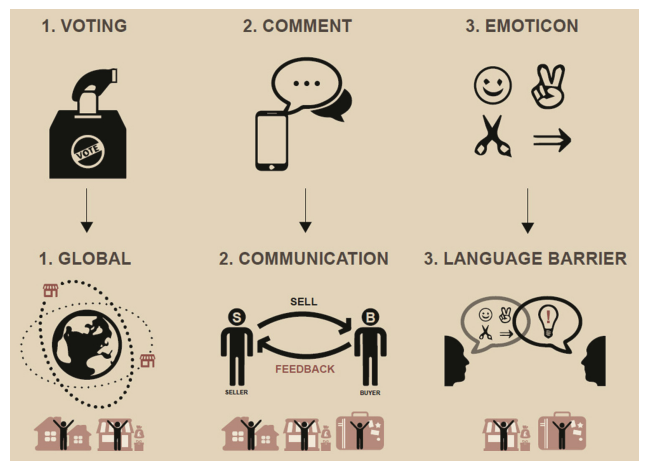

Fig. 2. Globalwall system (Source: student project outcome) 
London. Building a specific located communication technology or platform could create the conditions to stimulate inter-cultural trade (Fig. 2).

\subsection{Exploring the Category 2. Hybrid and Fusion}

This Tea Explorer example is an electronic plugin tool that creates the smells of a particular type of tea. It also includes a media application that explains the culture of brewing, and delivers a service to access the supply of different teas from different countries. This is about combining cultures to make a cross-cultural tool to sample multiple cultures of tea (Fig. 3).

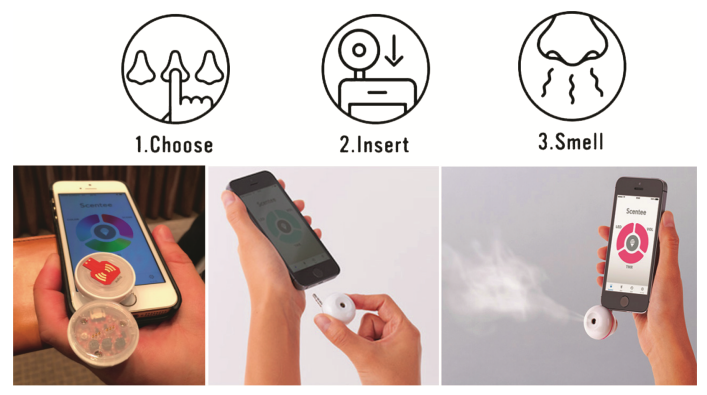

Fig. 3. Tea scent taster system (Source: student project outcome)

\subsection{Exploring the Category 3. Transform/Translate/Transplant}

Picnic bag for a city, London version.

The concept of the Picnicking bag of London is that the traditional Korean 'BOJAKIwrapping cloth' can be merged with the British picnic culture by creating a picnic mat which also transforms into a map of the city (Fig. 4).
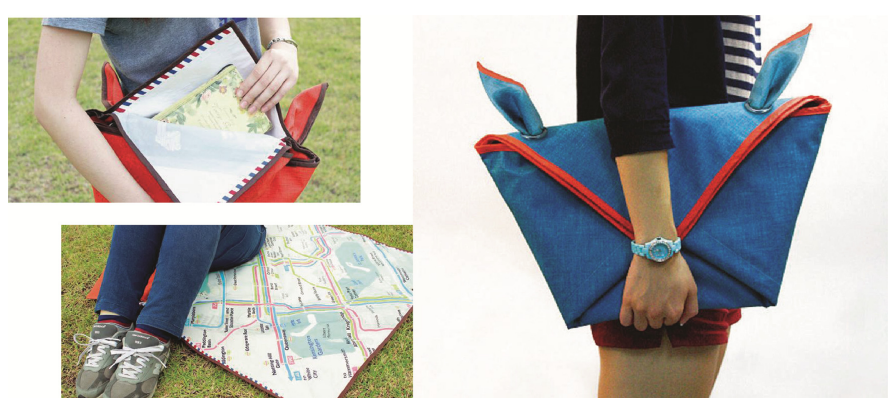

Fig. 4. Picnicking bag of London (Source: student project outcome) 


\subsection{Exploring the Category 3. Inclusion and Exclusion}

Digital Mirror of Shame

Different meanings shame in Europe and South Korean - Shame of Korean: beauty, Shame of European: obesity (Fig. 5)

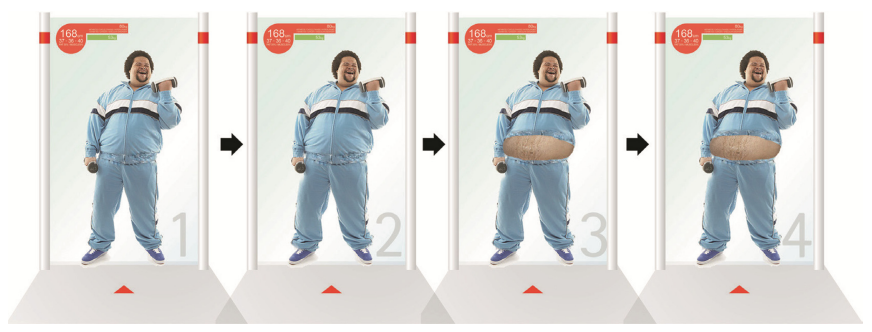

Fig. 5. The door of shame concept (Source: student project outcome)

This example from a student response to a brief that juxtaposing two different cultural sensibilities towards the concept of shame in the UK and in Korea. Interestingly while this would never become a product as it could offend its users, it exposes the nuances of Korean and British cultural attitudes to shame. This more in depth exploration of culture permits the students to explore the possible collisions of these attitudes within their design projects. There are clearly limitations to this approach, as it can often rely on preconceived notions and cultural stereotypes, which requires tutor encouragement to understanding culture through better contextual research.

\section{Conclusion}

This paper aimed to present how design tools can support the development of creative synergies and the understanding and respect of cultural diversities. Cross-cultural design, whilst respecting cultural diversity, can also protect and enhance particular cultures, national, regional and local. Designing is a cultural activity, and this tool locates the study of culture within the design curriculum. The territory of design is also rapidly shifting from physically manufactured goods to hybrid products that often combine manufactured goods, service and software. The audiences for these new designs are culturally interesting as they often span geographies, and create new forms of cultures through their user communities. Cross-cultural design tools are not just limited to use in undergraduate design learning, but are also relevant to innovation within multicultural communities, governments, organisations and businesses. 


\section{References}

Buchanan, R., Margolin, V.: Discovering Design. The University of Chicago Press, Chicago (1995a)

Buchanan, R., Margolin, V.: The Idea of Design. Massachusetts Institute of Technology Press, Cambridge (1995b)

Curedale, R.: Design Methods 2: 200 More Ways to Apply Design Thinking. Design Community College, Inc, Topanga (2012)

Diehl, J., Christianns, H.: Globalisation and cross-cultural product design. In: International Design Conference - Design 2006, Dubrovnik, Croatia (2006)

Douglas, S., Wind, Y.: The myth of globalization. Columbia J. World Bus. Winter, 19-29 (1987)

Ghose, R.: Design Development, Culture, and cultural legacies in Asia, Issues. Presented in International Conference, Design and Development in South and Southeast Asia (1988)

Hennessey, B.: Nurturing Creative Mindsets Across Cultures: A Toolbox for Teachers. Billund: The LEGO Foundation (2013). http://www.legofoundation.com/en-us/research-and-learning/ foundation-research/cultures-of-creativity/. Accessed 10 Oct 2014

Kolko, J.: Thoughts on Interaction Design. Morgan Kaufmann, Burlington (2010)

Runco, M.A.: Fostering Creativity Across Cultures. Billund: The LEGO Foundation (2013). http://www.legofoundation.com/en-us/research-and-learning/foundation-research/culturesof-creativity/. Accessed 10 Oct 2014

Turkle, S.: Evocative Objects: Things We Think With. MIT Press, Cambridge (2011)

Wolbers, T.: Three Pathways By Which Culture Can Influence Creativity. Billund: The LEGO Foundation (2013). http://www.legofoundation.com/en-us/research-and-learning/foundationresearch/cultures-of-creativity/. Accessed 10 Oct 2014 